\title{
PRODUÇÃO E VIABILIDADE DE OVOS DE RESISTÊNCIA DO CLADOCERA Daphnia magna Straus, 1820 EM CULTIVO INTENSIVO
}

\author{
GRAF, P.O.T.'; RESGALLA JR., C. ${ }^{1 *}$ \\ 1. Escola do Mar, Ciência e Tecnologia - Universidade do Vale do Itajaí - UNIVALI \\ *Corresponding author: cresgalla@univali.br
}

\begin{abstract}
Graf, P.O.T.; Resgalla Jr., C., 2017. Produção e viabilidade de ovos de resistência do cladocera Daphnia magna Straus, 1820 em cultivo intensivo. Braz. J. Aquat. Sci. Technol. 21(1). elSSN 1983-9057. DOI: 12993/bjast.v21n1. The objective of this work was to investigate the possibility of obtaining ephippia of Cladocera Daphnia magna, in large scale, for application in ecotoxicological tests. For this, different culture media were investigated to allow the maintenance of the organisms at high densities as well as to result in higher ephippia production. Likewise, the conditions that allowed a greater success of ephippia hatch rates were investigated. Finally, the sensitivity of juveniles originating from resistance eggs to reference toxicants was evaluated in comparison with the control chart of juveniles from conventional crops. As a result it was determined that the favorable system to obtain resistance eggs of Daphnia magna was in culture medium of high hardness (2 times higher than recommended). Under these conditions the ephippia had the highest hatching rates as well as a direct relationship between hatch rates and their age or storage time. An increase in hatchability rates of resistance eggs was obtained in standard culture medium under constant light at $20^{\circ} \mathrm{C}$ and pre-treated with sodium hypochlorite. Toxicity tests with potassium dichromate using the organisms from diapause stages indicated that sensitivity was similar to juveniles obtained under standard culture regimen.
\end{abstract}

Key Words: Ephippia, Ecotoxicology, Production, Stocking, Sensitivity

\section{INTRODUÇÃO}

Dos organismos utilizados em testes de toxicidade de água doce Daphnia magna é amplamente utilizada em programas de monitoramento ambiental, tanto na França como nos Estados Unidos da América (Knie \& Lopes, 2004). A U.S. Environmental Protection Agency (USEPA) indica o emprego da espécie na avaliação da toxicidade de compostos comumente aplicados na agricultura, tais como fertilizantes, fungicidas e inseticidas apresentando o grau de periculosidade e o potencial de risco de sua utilização (Nakagome et al., 2006). Apesar de não ser uma espécie alóctona, seu cultivo é amplamente difundido em todo o mundo, cuja a técnica é facilmente reproduzida segundo a norma da ABNT/NBR (2016).

O gênero Daphnia pertence a ordem Cladocera sendo popularmente chamada de pulgas d'água, devido principalmente a sua forma de locomoção. Estes organismos fazem parte do zooplâncton límnico, de importância na cadeia alimentar aquática, representando o elo entre organismos autotróficos e consumidores (Ruppert et al., 2005). Devido a este papel, efeitos observados nestes organismos inferem em problemas aos níveis tróficos subsequentes, destacando seu uso na avaliação de impacto ambiental, assim como, no estado de saúde do ambiente.

Estes organismos apresentam ainda uma particularidade de, quando sujeitos a condições naturais adversas a sua sobrevivência, tais como falta de ali- mento, competição, predação e temperatura, podem alterar a sua estratégia reprodutiva. Desta forma, quando em condições normais, a população de Cladocera é constituída somente por fêmeas diplóides que se reproduzem por partenogênese (reprodução assexuada com o desenvolvimento de um embrião sem que ocorra a sua fecundação) originando fêmeas idênticas a progenitora. Porém, em condições desfavoráveis, estas fêmeas diplóides produzem, assexuadamente, fêmeas e machos haplóides. Estes, sexuadamente, produzem ovos de resistências (efípios), que podem permanecer no ambiente por longos períodos no sedimento e quando eclodem, geram novas fêmeas diplóides quando as condições ambientais favoráveis são restabelecidas (Margalef, 1983; Ruppert et al., 2005).

Esta diapausa é observada em D. magna, sendo esses efípios de real relevância à sobrevivência desta espécie. Além da importância em termos genéticos esta estratégia reprodutiva visa também a dispersão no ambiente natural, possibilitando a difusão em diferentes ambientes devido a sua morfologia (presença de um espinho apical) que confere aderência em distintas superfícies. Além disto, podem oferecer proteção a ressecamentos, podendo suportar até a passagem por trato digestivo de peixes planctívoros, pássaros e mamíferos (Havel \& Shurin, 2004; Ruppert et al., 2005).

Outro ponto a ser destacado é a utilização destes organismos na aquicultura, ofertados como 
alimento natural, imprescindível para estágios iniciais de desenvolvimento de espécies de peixes de interesse comercial. $\mathrm{O}$ desenvolvimento de alimento vivo na aquicultura tem se mostrado vantajoso na substituição de dietas artificiais devido ao maior valor nutricional e por não comprometerem a qualidade da água de cultivo ocasionada pela decomposição da ração artificial ofertada em excesso (Luna-Figueiroa, 1999; Takahashi et al., 2010).

Para os laboratórios de ecotoxicologia, a utilização de organismos cultivados envolvem problemas de custos, tempo e mão de obra especializada. Entretanto, a existência da possibilidade da estocagem de organismos em estado de diapausa, como acontece com cistos de Artemia salina, seria uma facilidade para os laboratórios, envolvendo também empresas de consultoria ambiental assim como na aquicultura, permitindo o seu mais diverso uso nas diferentes áreas das ciências ambientais.

Desta forma o objetivo deste trabalho foi investigar a produção e a viabilidade de efípios do Cladocera $D$. magna em condições de cultivo intensivo em laboratório para a sua aplicação em ensaios ecotoxicológicos.

\section{METODOLOGIA}

\section{Pré-cultivo}

Os cultivos de $D$. magna foram realizados no Laboratório de Ecotoxicologia da Universidade do Vale do Itajaí (UNIVALI) conforme protocolo descrito na ABNT/NBR (2016), em água de fonte natural com a adição das quatro primeiras soluções para a correção da dureza (Tabela 1). As matrizes foram mantidas e acondicionadas em recipientes de vidro com 2,8 litros, sempre respeitando a densidade proposta pela ABNT ( 25 adultos $L^{-1}$ ), o que forneceram os juvenis para início do cultivo intensivo e principalmente para a elaboração da carta controle de sensibilidade frente a um tóxico de referência.

Tabela 1 - Soluções para meio de cultivo de $D$. magna e valores da dureza total para cada meio de cultivo e água natural utilizada.

\begin{tabular}{|c|c|c|c|c|c|c|}
\hline \multirow{2}{*}{$\begin{array}{l}\text { Reagentes e } \\
\text { Dureza da água }\end{array}$} & \multirow{2}{*}{ Fórmula } & \multirow{2}{*}{$\begin{array}{c}\text { Concentração das } \\
\text { soluçốes estoque } \\
\left(\mathrm{g} \mathrm{L}^{-1}\right)\end{array}$} & \multicolumn{4}{|c|}{ Cultivos e volume em $\mathrm{mL} \mathrm{L}^{-1}$} \\
\hline & & & $200 \%$ & $100 \%$ & $50 \%$ & $0 \%$ \\
\hline Cloreto de cálcio & $\mathrm{CaCl}_{2} \cdot 2 \mathrm{H}_{2} \mathrm{O}$ & 73,5 & 6,4 & 3,2 & 1,6 & - \\
\hline $\begin{array}{l}\text { Sulfato de } \\
\text { magnésio } \\
\text { Cloreto de }\end{array}$ & $\mathrm{MgSO}_{4} \cdot 7 \mathrm{H}_{2} \mathrm{O}$ & 123,3 & 1,6 & 0,8 & 0,4 & - \\
\hline $\begin{array}{l}\text { potássio } \\
\text { Bicarbonato de }\end{array}$ & $\mathrm{KCl}$ & 5,8 & 1,6 & 0,8 & 0,4 & - \\
\hline sódio & $\mathrm{NaHCO}_{3}$ & 64,8 & 1,6 & 0,8 & 0,4 & - \\
\hline $\begin{array}{l}\text { Média da dureza } \\
\text { total em mg }\end{array}$ & $\mathrm{CaCO}_{3} \mathrm{~L}^{-1}$ & & 320 & 177 & 78 & 12 \\
\hline
\end{tabular}

Os cultivos intensivos foram realizados em bombonas plásticas de 20 litros, em forma de funil para permitir o dreno de detritos orgânicos, tais como, algas e organismos mortos, ecdises e principalmente os efípios, que depois de formados, sedimentam. As bombonas foram preenchidas com 15 litros de água doce natural enriquecida com meio de cultura.

\section{Cultivos intensivos para a produção de efípios}

Os cultivos intensivos foram realizados com distintos meios. O primeiro meio foi o uso da própria água natural, denominada " $100 \%$ ", que representou a adição das soluções do meio de cultivo nas concentrações propostas na ABNT/NBR (2016). O segundo método foi a utilização da água da mesma fonte natural com metade da adição das soluções do meio de cultivo, chamado de " $50 \%$ ". O terceiro tratamento utilizou apenas da água desta fonte natural sem adição das soluções do meio de cultivo, denominado " $0 \%$ " e por fim, foi realizado o tratamento " $200 \%$ ", que apresentou o dobro do volume das soluções do meio de cultivo (Tabela 1).

Para o cultivo foi utilizado a água proveniente de uma nascente natural do bairro de Cabeçudas localizada no município de Itajaí (SC). Esta fonte natural fornece água aos moradores da região e apresenta parâmetros favoráveis a manutenção da $D$. magna, como o oxigênio dissolvido geralmente acima dos 8 $\mathrm{mg} \mathrm{L}^{-1}$ e $\mathrm{pH}$ entre 7,0 a 8,0 conforme recomenda a norma da ABNT/NBR (2016).

Com relação à dureza, a água proveniente da fonte sempre apresentou baixos valores, não excedendo as $12 \mathrm{mg} \mathrm{CaCO}_{3} \mathrm{~L}^{-1}$ de dureza total, segundo método Spectroquant ${ }^{\circledR}$ (MERCK). Desta forma, houve a necessidade do enriquecimento com meio de cultivo para a correção das propriedades físico-químicas da água segundo a Tabela 1.

Os cultivos foram realizados com fraca aeração e a manutenção foi realizada semanalmente, sempre verificando valor de $\mathrm{pH}$, a coleta dos efípios e a estimativa das densidades dos organismos dentro dos tanques mediante o uso de cinco subamostragens, com posterior retorno ao cultivo. O aumento da densidade dentro dos tanques era proporcionado pela própria reprodução dos organismos e pela introdução de juvenis provenientes do cultivo das matrizes de forma tradicional como descrito no pré-cultivo.

As renovações da água dos tanques envolveram $60 \%$ de seu volume total semanalmente. A água drenada dos tanques passava por uma malha de $75 \mu \mathrm{m}$ para a retirada manual de efípios e de dáfnias vivas. As dáfnias eram retornadas aos tanques e os efípios eram lavados com $500 \mathrm{~mL}$ de água destilada sobre a malha $25 \mu \mathrm{m}$, com auxílio de um pissete, e estocados em tubos do tipo eppendorf com água destilada e acondicionados no escuro, para evitar sua eclosão. A densidade de estocagem foi em média de 200 efípios por $1,5 \mathrm{~mL}$ de água destilada.

Todos os cultivos da $D$. magna foram alimen- 
tados com a microalga Scenedesmus subspicatus, ofertados conforme ABNT/NBR (2016), respeitando a densidade de $10^{6} \mathrm{cel} \mathrm{mL}^{-1}$ por dáfnia e cinco vezes por semana. O cultivo da alga foi realizado segundo ABNT/NBR (2016), porém utilizou-se o meio de cultivo $\mathrm{CHU}$ (Chu, 1942) que promoveu um maior crescimento das microalgas.

\section{Eclosão dos efípios}

Ensaios preliminares foram realizados para identificar o melhor método de eclosão dos efípios. Os primeiros ensaios, sem sucesso, envolveram um choque térmico (de 4 a $21^{\circ} \mathrm{C}$ ), antes das condições de eclosão em meio de cultura, sendo incubados na temperatura de $20 \pm 1^{\circ} \mathrm{C}$ com luz constante. Também sem sucesso envolveu a incubação em meio com microalga fresca (Scenedesmus subspicatus) e em solução ultrassonificada da mesma alga e nas mesmas condições anteriores de temperatura e luz. Por fim, testou-se a eclosão frente ressecamento overnight antes das condições de eclosão, o que gerou uma grande variabilidade dos resultados sendo então abandonada.

Em base dos resultados anteriores buscou avaliar o sucesso de eclosão nas condições padrões de incubação (meio de cultura a $20 \pm 1^{\circ} \mathrm{C}$ e luz constante) em função da origem dos efípios (meio de cultura intensivo) e de sua idade (tempo de encistamento el ou estocagem).

Por fim, foram realizados ensaios envolvendo o uso do hipoclorito de sódio (cloro comercial ou água sanitária) a 0,15\% em diferentes tempos de exposição (15, 30 e 60 minutos). Este processo exigiu uma lavagem dos efípios em água destilada por 1 hora logo após sua exposição em hipoclorito de sódio. Após este processo os efípios foram dispostos para eclosão em meio de cultura em luz constante sob uma temperatura de $20^{\circ} \mathrm{C}$.

\section{Avaliação de sensibilidade dos juvenis frente ao tóxico de referência}

Além da reposição de organismos para o cultivo intensivo, a produção dos cultivos tradicionais foi destinada para a montagem da carta controle de sensibilidade mediante a realização de ensaios com o tóxico de referência dicromato de potássio $\left(\mathrm{K}_{2} \mathrm{Cr}_{2} \mathrm{O}_{7}\right)$.

Para os testes de toxicidade da carta controle foram utilizados juvenis de 2 a 26 horas de vida, não sendo alimentados antes do ensaio. Nestes testes, foram expostos 20 juvenis por concentração do dicromato de potássio, em duplicata, em um recipiente contendo $40 \mathrm{~mL}$ da solução teste e incubação em $21^{\circ} \mathrm{C}$ com fotoperíodo 16:8. Foram utilizadas cinco concentrações do dicromato de potássio, mais o tratamento controle (meio de cultura). A cada 24 horas foi avali- ada a redução da mobilidade dos organismos teste e ao final das 48 horas estimado a $\mathrm{CE}_{50}$ (Concentração Efetiva Mediana) pelo método Trimmed SpearmanKarber (USEPA, 2002).

O mesmo procedimento foi realizado para os juvenis obtidos dos efípios obtidos nos cultivos intensivos. Para tal, juvenis eclodidos do tratamento com hipoclorito de sódio a $0,15 \%$ provenientes do cultivo $200 \%$, e com tempo de eclosão de 3-4 dias e de 5 a 6 dias foram utilizados nos ensaios. Sua sensibilidade foi avaliada a partir dos valores de $\mathrm{CE}_{50}$ para o dicromato de potássio em relação a carta controle de juvenis, provenientes dos cultivos tradicionais.

\section{RESULTADOS}

\section{Cultivo intensivo}

Os parâmetros físico-químicos de oxigênio dissolvido e $\mathrm{pH}$ se mantiveram dentro do intervalo recomendado para o cultivo dos organismos, ou seja, acima de $1 \mathrm{mg} \mathrm{L}^{-1}$ e entre 7 e 8 , respectivamente, em 350 dias de cultivo.

Os picos de densidades assim como o aparecimento dos efípios começaram em média no $40^{\circ}$ dia de cultivo em todos os tratamentos. As estimativas de densidades forneceram indicativos sobre a saúde do cultivo, fato observado pela sua sustentação. A produção de efípios, associado às maiores densidades, favoreceu a geração de ovos de resistência com padrão morfotípico de aparência translucida e de fácil visualização dos núcleos (Fig. 1), sendo estas as formas predominantes nos cultivos intensivos.

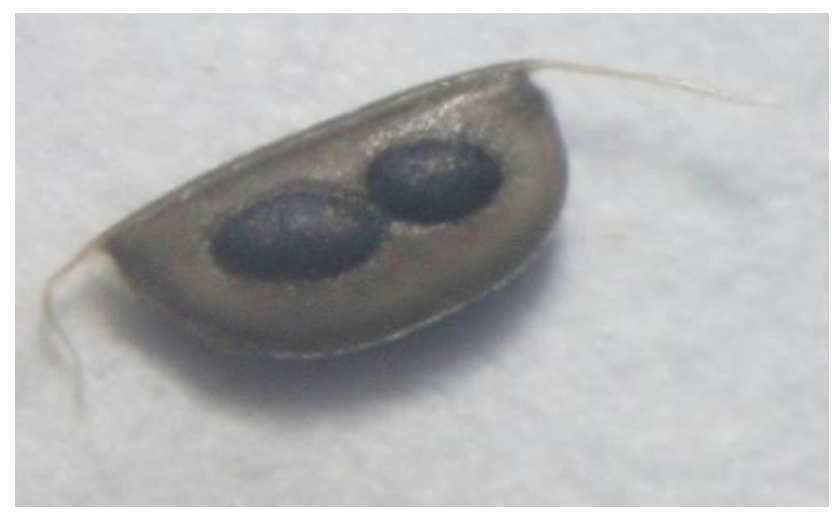

Figura 1 - Exemplo de um efípio de Daphnia magna de 1,37 mm predominante nos cultivos intensivos (translucido).

A manutenção empregada semanalmente visou não só a melhoria das condições no cultivo, mas também proporcionou o melhor método de obtenção de efípios com o aumento da densidade, não só pela própria produção, mas também pela inclusão de juvenis provenientes dos cultivos das matrizes. Os diferentes meios de cultivo utilizados influenciaram na sustentabilidade das densidades e na produção de 
efípios. Assim, o cultivo de 50\% manteve uma densidade duas vezes superior a obtida em água natural sem adição de meio (0\%). E foi similar ao tratamento de $100 \%$ do meio de cultura. Entretanto, no tratamento com o dobro da dureza $(200 \%)$ foi observado as maiores densidades médias o que favoreceram uma maior produção de efípios (Fig. 2).

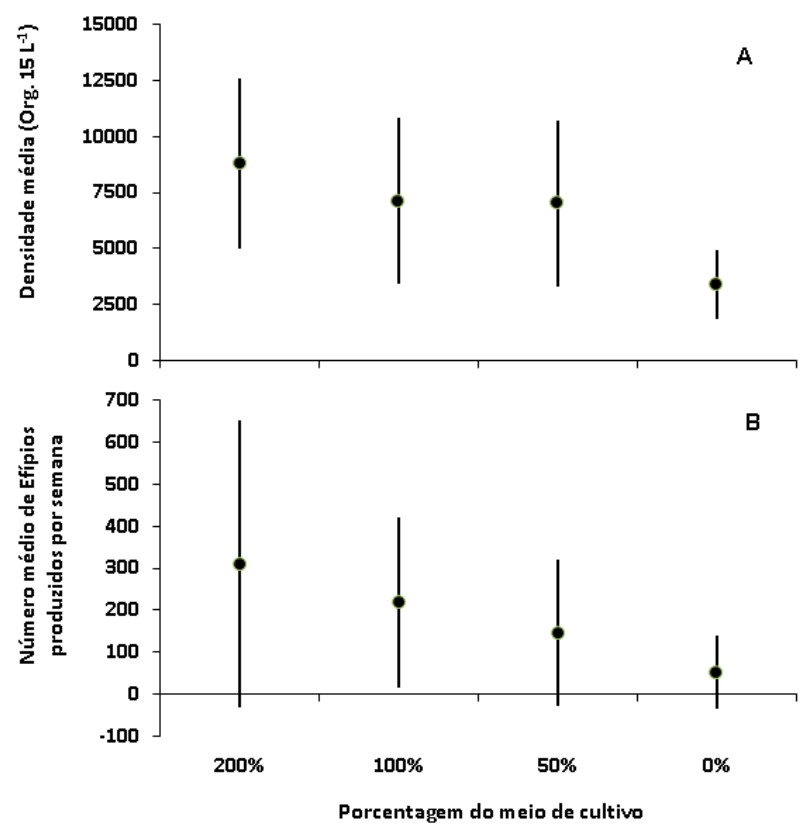

Figura 2 - Valores médios (ponto) e desvio padrão (linha) de (A) densidade de Cladocera (Org. 15 L-1) e (B) da produção dos efípios por semana para cada método de cultivo ao longo de toda a manutenção. Sendo: $0 \%$ água doce natural sem meio de cultivo, $50 \%$ a água doce natural com $50 \%$ do meio de cultivo; $100 \%$ = água doce natural com $100 \%$ do meio de cultivo e $200 \%$ = água doce natural com $200 \%$ do meio de cultivo.

\section{Estocagem}

Inicialmente, foi testada a estocagem de efípios em diferentes densidades (200 efípios em 1,5 mL; 7,0 e $20,0 \mathrm{~mL}$ ) em meio de cultivo e no escuro para evitar possíveis eclosões segundo as recomendações de Boersma et al. (2000). Como foram observadas eclosões nas estocagens nas menores densidades $(7,0$ e $20,0 \mathrm{~mL})$ foi adotado para a técnica a manutenção de uma relação número de efípios/volume de estocagem o mais alto possível. Assim os efípios passaram a ser estocados em tubos do tipo Eppendorf de $1,5 \mathrm{~mL}$ em densidades superiores a 200 .

Além da escolha das condições de densidade de estocagem, o meio ao qual os efípios foram submetidos esteve intimamente relacionado com sua viabilidade. Desta forma, baseado em testes prévios (dados não apresentados), o meio de estocagem que melhor evitou a eclosão dos efípios foi em água com baixas concentrações de sais, especificamente em água destilada. Assim, em todos os ensaios realizados neste trabalho foram utilizados efípios estocados em alta densidade, em água destilada e no escuro.

\section{Eclosão e Sensibilidade}

Os ensaios com eclosão dos efípios foram realizados em meio de cultura, sob luz constante e a $20^{\circ} \mathrm{C}$. Uma vez padronizado foi constatado que os efípios obtidos no tratamento em $200 \%$ do meio de cultura, apresentaram as maiores taxas de eclosão em relação aos demais tratamentos (Fig. 3).

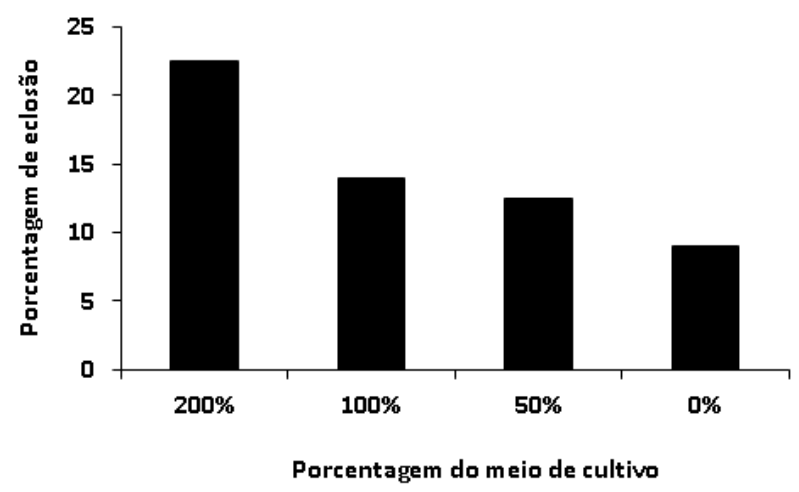

Figura 3 - Porcentagem de eclosão (\%) de efípios obtidos em diferentes meios de cultivo intensivo (idade dos efípios de 37 dias). Sendo: $0 \%=$ água doce natural sem meio de cultivo, $50 \%=$ água doce natural com $50 \%$ do meio de cultivo; $100 \%$ = água doce natural com $100 \%$ do meio de cultivo e $200 \%$ = água doce natural com $200 \%$ do meio de cultivo.

Da mesma forma, as maiores taxas de eclosões estiveram associadas a idade do efípio ou o seu tempo de estocagem (Fig. 4).

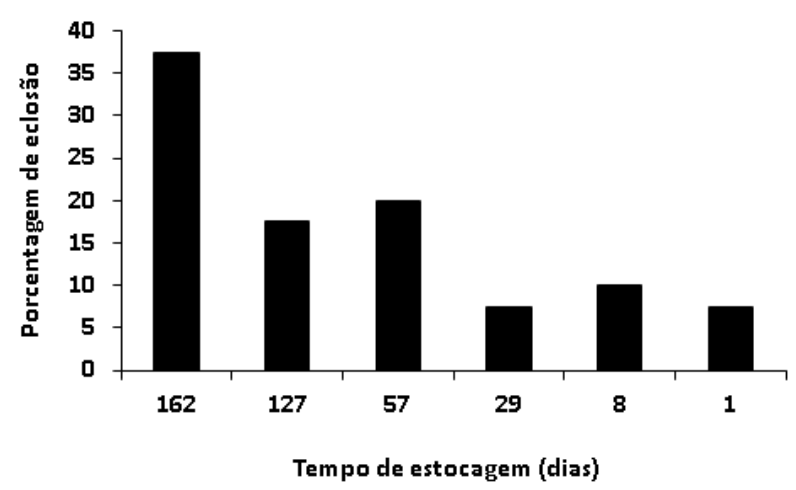

Figura 4 - Porcentagem de eclosão (\%) de efípios em função do seu tempo de encistamento e estocagem.

Similar às técnicas aplicadas para cisto em Artemia salina (Støttrup \& McEvoy, 2003), foi aplicado o método de descapsulação, com o uso do cloro comercial (hipoclorito de sódio a 0,15\%) em diferentes tempos de exposição. Os resultados indicaram que o cloro acima de 30 minutos promove uma melhoria na taxa de eclosão (Fig. 5). O uso de cloro em maiores concentrações e com menor tempo de exposição não apresentou melhoria no sucesso das taxas de eclosão dos efípios. 


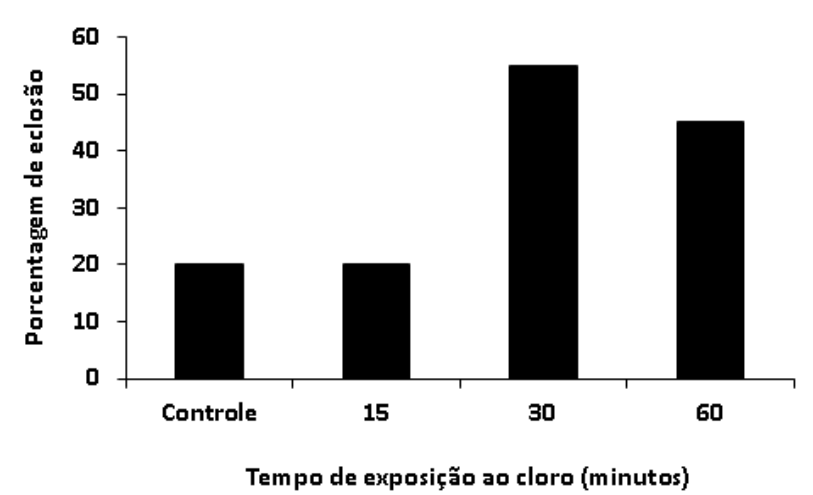

Figura 5 - Porcentagem de eclosão (\%) de efípios tratados com hipoclorito de sódio (idade dos efípios de 560 dias).

Juvenis eclodidos entre 3 a 4 dias após tratamento com hipoclorito de sódio, assim como, os obtidos no $5^{\circ}$ e $6^{\circ}$ dias foram utilizados em ensaios, frente ao dicromato de potássio (Fig. 6). Estes resultados indicaram que a sensibilidade dos juvenis não é alterada com a sua origem (se de ovos de resistência ou de cultivos normais) e com o tempo de sua eclosão (saída do seu estado de dormência). A norma da ABNT/NBR (2004) recomenda que os juvenis, utilizados em ensaios ecotoxicológicos, devem respeitar a idade máxima de 48 horas de idade. Para os juvenis obtidos de efípios neste trabalho, não foram ultrapassados 6 dias de incubação para seu emprego em ensaios ecotoxicológicos.

\section{DISCUSSÃO}

No que diz respeito à produção de alimento vivo, o cultivo de invertebrados aquáticos sempre foi um fator limitante nas práticas de aquicultura (Støttrup \& McEvoy, 2003; Takahashi et al., 2010), assim como na obtenção de organismos teste em ensaios ecotoxicológicos (Knie \& Lopes, 2004). Desta forma, técnicas de permitam a obtenção de organismos na forma de diapausa são uma vantagem no fornecimento e na utilização em práticas biológicas. Em atendimento a estas necessidades, o presente trabalho, apresenta uma técnica de produção e utilização de efípios de D. magna, de forma simples e segura.

O sucesso no cultivo de dáfnia em altas densidades e na produção de efípios em meio de cultura em alta dureza provavelmente reflete as exigências fisiológicas da espécie. Resultado similares em termos de densidade de cultivo também foram obtidas por Lewis \& Maki (1981) com altas produções de juvenis em cultivos de água de alta dureza. Por outro lado, Doma (1979) destaca que o estímulo para prevalecer a reprodução gametogênica (produção de efípios), nos cultivos de dáfnia, seria limitar a dieta com microalgas em favorecimento de detritos e bactérias, associado com alterações na intensidade de luz e temperatura. De certa forma, os cultivos intensivos desenvolvidos neste trabalho podem ter estimulado a produção

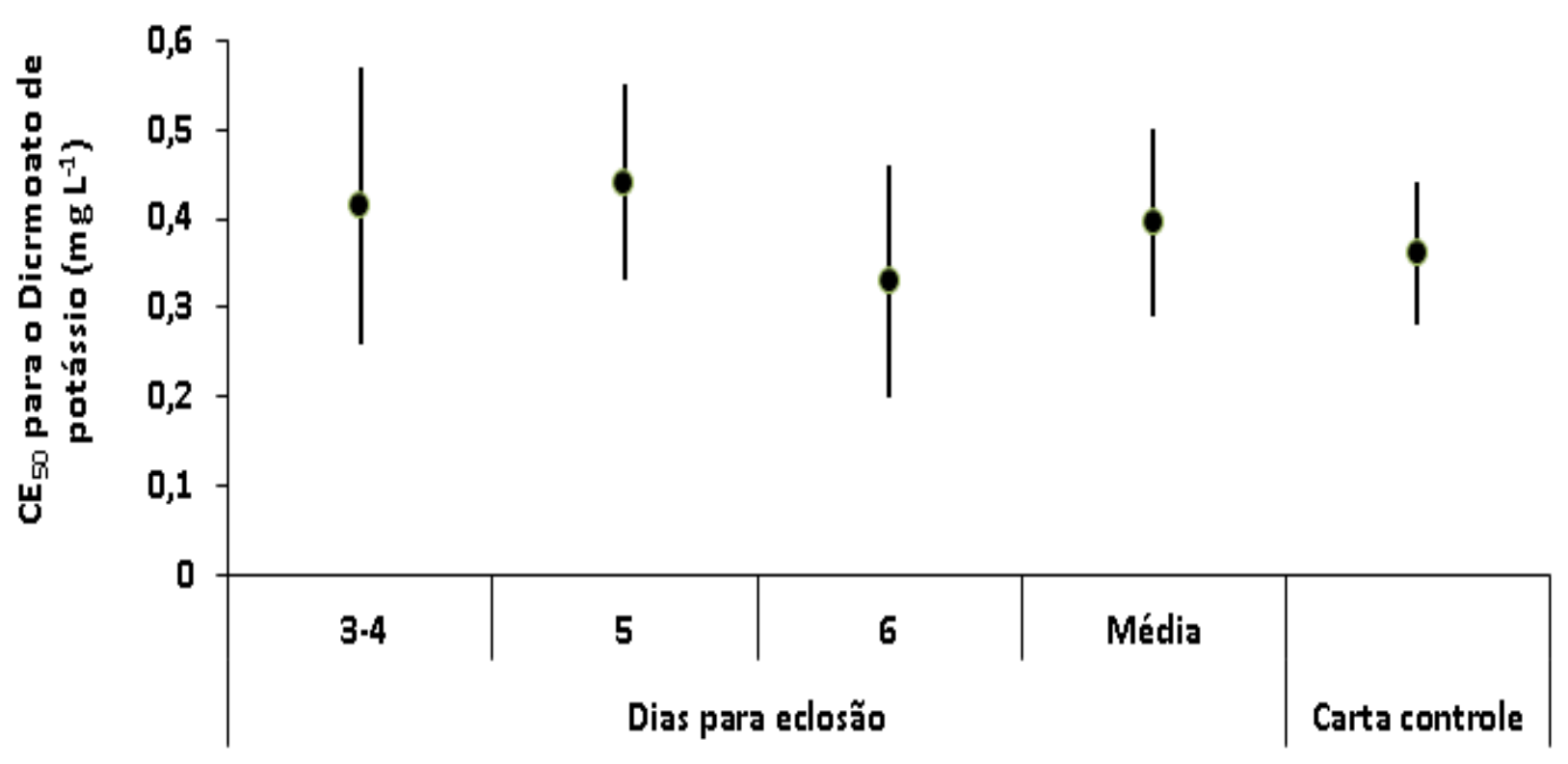

\section{Origem dos neonatos}

Figura 6 - Valores médios (ponto) e desvio padrão (linha) da CE50 para a dicromato de potássio obtidos em testes de toxicidade de juvenis de Daphnia magna oriundos de efípios com diferentes diasde eclosão e de juvenis obtidos de cultivos tradicionais (carta controle). Idade dos efípios de 560 dias. 
detrítica dentro dos tanques, o que pode também ter contribuído para a produção de efípios nos tratamentos testados.

A manutenção do encistamento ou a estocagem dos efípios vai em direção contrária aos estímulos externos que promovam a sua eclosão. Assim, a manutenção dos efípios no escuro ou sem luminosidade (Vandekerkhove et al., 2005), concentração de sais na água de manutenção (Rojas et al., 2001) e altas densidades (que aumente a comunicação física entre os efípios) podem ser esperados como inibidores de sua eclosão.

Pelo contrário, a grande maioria dos trabalhos sobre a interrupção do estágio de diapausa dos efípios de Cladocera envolve o emprego da temperatura como o agente indutor (Stross, 1969; Weider, 1997; Vandekerkhove et al., 2005; Pauwels et al., 2007), ou seja, exige-se uma redução da temperature e seu aumento posterior para induzir a eclosão. Nesta mesma linha, Boersma et al. (2000) afirmaram que a presença de alimento durante o período de incubação refletiu num estímulo positivo a eclosão do efípio. Segundo Vandekerkhove et al. (2005), a eclosão pode ser estimulada também por resfriamento a seco anterior a sua incubação em condições padrões, ou simplesmente pela sua secagem no ar e à temperatura ambiente (Doma, 1979). Apesar destas técnicas, o sucesso do percentual de eclosão ainda é muito limitado.

Estudos realizados sobre o sucesso na eclosão dos efípios envolvem hipóteses desde o investimento maternal (Ricci, 2001), assim como, a necessidade de um tempo mínimo de encistamento para maior viabilidade no nascimento (Meester \& De Jager, 1993). Estas hipóteses, de certa forma, podem ser atribuídas nos resultados apresentados neste trabalho, pois efípios originados de cultivos em condições ideais (tratamento $200 \%$ ) e com maior tempo de encistamento (maior que 160 dias) apresentaram as maiores taxas de eclosão.

De forma similar, Paes et al. (2016) destacaram que a descapsulação dos efípios foi fundamental para aumentar as taxas de eclosão, e o uso de cloro atuou como um facilitador no processo, como também observado neste trabalho.

Devido à grande aplicação dos ensaios de toxicidade de $D$. magna em nível mundial, atualmente existem no mercado "kits" contendo os materiais necessários e protocolos de execução de ensaios para diferentes espécies do gênero Daphnia como a $D$. pulex e D. magna. O uso destes kits foi impulsionado pela fácil aplicação e redução de custos operacionais devido ao uso dos efípios. Para o organismo modelo deste trabalho, autores como Kaza et al. (2007); Arias-Barreiro et al. (2010) e Sirtori (2010) afirmam sua aplicabilidade e resposta similar dos juvenis frutos de efípios para testes toxicidade aguda em relação a juvenis originários de culturas convencionais confirmando os resultados obtidos neste trabalho. Na mesma linha, Doma (1979) também propõe o uso direto de efípios nos ensaios e utiliza as taxas de eclosão como critério de endpoint.

\section{CONCLUSÕES}

O sistema de cultivo favorável à obtenção de estágios de diapausa de $D$. magna foi o de alta densidade e em água de alta dureza.

A técnica de estocagem dos efípios recomendada é em água destilada, em alta relação de efípios/ volume, no escuro e à temperatura ambiente.

O melhor método de incubação para eclosão dos efípios foi sob luz constante em temperatura de $20^{\circ} \mathrm{C}$ em meio de cultura com tratamento prévio de hipoclorito de sódio. Efípios mais velhos tendem a apresentar maiores taxas de eclosão, assim como, efípios obtidos em culturas de alta dureza.

Ensaios de sensibilidade com organismos provenientes de efípios podem ser utilizados na avaliação da toxicidade aguda, uma vez que a sua sensibilidade foi similar aos juvenis obtidos em regime de cultivo tradicional.

\section{REFERÊNCIAS}

Associação Brasileira de Normas Técnicas, ABNT/ NBR. 2016. Ecotoxicologia aquática - toxicidade aguda - método de ensaio com Daphnia spp (Cladocera, Crustacea). ABNT/NBR 12713. 27p.

Arias-Barreiro, C.R.; Nishizaki, H.; Okubo, K.; Aoyama, I \& Mori, I.C. 2010. Ecotoxicological characterization of tannery wastewater in Dhaka, Bangladesh. J. Envir. Biol. India. 4:471-475.

Boersma, M.; Boriss, H. \& Mitchell, S.E. 2000. Maternal effects after sexual reproduction in Daphnia magna. J. Plankton Res. 22(2):279-285.

Chu, S.P. 1942. The influence of the mineral composition of the medium on the growth of planktonic algae. Part I. Methods and culture media. J. Ecol. p. 284-325.

De Meester, L. \& De Jager, H. 1993. Hatching of Daphnia sexual eggs. II. The effect of age and a second stimulus. Freshwater Biol. 30:227-233.

Doma, S. 1979. Ephippia of Daphnia magna Straus A technique for their mass production and quick revival. Hydrobiologia. 67(2):183-188.

Havel, J.E. \& Shurin, J.B. 2004. Mechanisms, effects, and scales of dispersal in freshwater zooplankton. Limnol. Oceanogr. 2(49):1229-1238.

Kaza, M.; Mankiewicz-Boczek, J.; Izydorczyk, K. \& Sawicki, J. 2007. Toxicity assessment of water samples from rivers in central Poland using a 
battery of microbiotests - a pilot study. Polish. J. Environ., Poland. 1(16):81-89.

Knie, J.L.W. \& Lopes, E.W.B. 2004. Testes ecotoxicológicos: métodos, técnicas e aplicações. Florianópolis: FATMA:GTZ. 289p.

Lewis, M.A. \& Maki, A.W. 1981. Effects of water hardness and diet on productivity of Daphnia magna Straus. in laboratory culture. Hydrobiologia. 85(2):175-179.

Luna-Figueiroa, J. 1999. Influencia de alimento vivo sobre la reproducción y crecimiento del ángel Pterophyllum scalare (Perciformes: Cichlidae). Acta Universitaria, México. pp. 21-29.

Margalef, R. 1983. Limnologia. Editora Omega, Barcelona. 1010p.

Nakagome, F.K; Noldin, J.A. \& Resgalla Jr., C. 2006. Toxicidade aguda e análise de risco de herbicidas e inseticidas utilizados na lavoura do arroz irrigado sobre o cladócero Daphnia magna. Pesticidas: ecotoxicologia e meio ambiente. 16:93-100.

Paes, T.A.S.V.; Rietzler, A.C. \& Maia-Barbosa, P.M. 2016. Methods for selection of Daphnia resting eggs: the influence of manual decapsulation and sodium hypoclorite solution on hatching rates. Braz. J. Biol. 76(4):1058-1063.

Pauwels, K.; Stoks, R.; Verbiest, A. \& De Meester, L. 2007. Biochemical adaptation for dormancy in subitaneous and dormant eggs of Daphnia magna. Hydrobiologia. 594(1):91-96.

Ricci, C. 2001. Dormancy patterns in rotifers. Hydrobiologia. 446:1-11.

Rojas, N.E.T.; Marins, M.A. \& Rocha, O. 2001. The effect of abiotic factors on the hatching of Moina micrura Kurz, 1874 (Crustacea: Cladocera) ephippial eggs. Braz. J. Biol. 61(3):371-376.

Ruppert, E.E; Fox, R.S. \& Barnes, R.D. 2005. Zoologia dos Invertebrados: uma abordagem functionalevolutiva. $7^{\text {a }} \mathrm{Ed}$, pp.720-933.
Sirtori, C. 2010. Evaluación analítica de procesos de transformación biológica, fotoquímica y fotocatalítica de fármacos em agua. Tese de Doutorado - Departamento de Centro de Investigaciones Energéticas, Medioambientales Y Tecnológicas, Universidad de Almería, Almería. 340p.

Støttrup, J.G. \& McEvoy, L.A. 2003. Live feeds in marine aquaculture. Blackwell Publishing, Oxford, 318p.

Stross, R.G. 1969. Photoperiod control of diapause in Daphnia. Two stimulus control of long-day, shortday induction. Biol. Bull. 137:359-374.

Takahashi, L.S.; da Silva, T.V.; Fernandes, J.B.K.; Biller, J.D. \& Goncalves de Sandre, L.C. 2010. Efeito do tipo de alimento no desempenho produtivo de juvenis de acará-bandeira (Pterophyllum scalare). Bol. Inst. Pesca. 36(1):1-8.

United States Environmental Protection Agency. USEPA, 2002. Short-term methods for estimating the chronic toxicity of effluents and receiving waters to freshwater organisms. Fourth Edition. Washington, EPA-821-R-02-013.

Vandekerkhove, J.; Declerck, S.; Brendonck, L.; Conde-Porcuna, J.M.; Jeppesen, E. \& De Meester, L. 2005. Hatching of cladoceran resting eggs: temperature and photoperiod. Freshwater Biol. 50(1):96-104.

Weider, L.J.; Lampert, W.; Wessels, M.; Colbourne, J.K. \& Limburg, P. 2007. Long-term genetic shifts in a microcrustacean egg bank associated with anthropogenic changes in the Lake Constance ecosystem. Proc. Biol. Sci. 264(1388):1613-1618.

\footnotetext{
Submetido: Maio/18 Revisado: Maio/18 Aceito:Junho/18 Publicado: 15 de Agosto/18
} 